\title{
Self-management in neurological disorders: Systematic review of the literature and potential interventions in multiple sclerosis care
}

\author{
Alex D. Rae-Grant, MD; ${ }^{1}$ Aaron P. Turner, PhD; ${ }^{2-3 *}$ Alicia Sloan, MSW, MPH; ${ }^{2}$ Deborah Miller, PhD; ${ }^{1}$ James $^{2-4}$ \\ Hunziker, ARNP; ${ }^{2}$ Jodie K. Haselkorn, MD, MPH $^{2-4}$ \\ ${ }^{1}$ Mellen Center for Multiple Sclerosis Treatment and Research, Cleveland Clinic, Cleveland, $\mathrm{OH} ;{ }^{2} \mathrm{Multiple}$ Sclerosis \\ Center of Excellence West, Department of Veterans Affairs Puget Sound Health Care System, Seattle, WA; Departments \\ of ${ }^{3}$ Rehabilitation Medicine and ${ }^{4}$ Epidemiology, University of Washington, Seattle, WA
}

\begin{abstract}
Our objective was to review the current body of evidence supporting the efficacy of self-management programs in individuals with multiple sclerosis (MS) and other chronic neurological conditions. We reviewed published literature using standardized search terms; examined self-management interventions in a variety of chronic neurological disorders, including MS; and classified studies using the evidence classification established by the American Academy of Neurology. We reviewed 527 abstracts, of which 39 met our inclusion criteria for evaluation. Of the 39 studies, 3 provided class I evidence assessing the efficacy of self-management interventions: a randomized controlled trial of a telephone counseling program for health promotion in MS, a home-based exercise program for reducing falls in people with Parkinson disease, and the comparison of a fitness center program versus a home-based exercise program for people with traumatic brain injury. The remaining studies provided additional support for self-management interventions with a lesser degree of methodologic rigor (class II, class III, or class IV evidence). We concluded that self-management strategies are applicable to chronic neurological diseases, but a need exists for more rigorous studies in this area. We provide recommendations for future intervention study methodologies with a specific emphasis on MS care.
\end{abstract}

Key words: chronic illness, headache, multiple sclerosis, neurological, Parkinson disease, self-care, self-management, stroke, systematic review, traumatic brain injury.

\section{INTRODUCTION}

Multiple sclerosis (MS) is a degenerative disorder of the central nervous system affecting as many as 350,000 persons in the United States [1]. Its presentation varies, but typically includes both acute exacerbations and remissions as well as chronic progression of disability over time. It is associated with heterogeneous symptoms that include, but are not limited to, sensory and motor loss, fatigue, difficulties with balance and sexual functioning, pain, cognitive impairment, and depression [25]. MS is typically diagnosed in patients between the ages of 20 and 40 and is associated with a relatively normal lifespan. As a result, individuals often face the challenge of a prolonged course of illness [1].

Providing care for chronic neurological diseases such as MS occurs in a framework much different from the

Abbreviations: AAN = American Academy of Neurology, CCM = Chronic Care Model, MS = multiple sclerosis, RCT = randomized controlled trial, SF-36 $=36$-Item Short Form Health Survey, VA = Department of Veterans Affairs.

* Address all correspondence to Aaron P. Turner, PhD; VA Puget Sound Health Care System, Rehabilitation Care Service, S-117-RCS, 1660 S. Columbian Way, Seattle, WA 98108; 206-277-6134; fax: 206-764-2263.

Email: Aaron.Turner@va.gov

DOI:10.1682/JRRD.2010.08.0159 
treatment of acute episodic diseases for several reasonspersons with MS have an ongoing disorder that requires monitoring and management, and health services delivery is often provided by multiple providers and in different healthcare settings. Care may not focus on urgent issues as much as on preparation, planning, and maintenance to avoid the development of urgent issues. It is important that individuals with MS understand their disorder so that they take charge of as many aspects of managing MS and its associated impairments as possible [6].

The Chronic Care Model (CCM) is a frequently cited methodology used to frame disease care in a measurable, iteratively modifiable setting that can be applied to multiple disease states [7]. The CCM is premised on the concept that the processes healthcare providers use for acute care are poorly designed for use with chronic illnesses [8]. This model is divided into various elements designed to assess all aspects of care and provide decision support tools and self-assessment strategies for healthcare teams [9-10]. The CCM has helped reframe the concept of chronic disease management from a healthcare providerfocused endeavor to a systems-based activity. A significant component of the CCM is a person who is active and informed about his or her health condition and is able to use self-management strategies.

For many chronic conditions, individuals and their caregivers either provide substantial portions of their own care or could do so if their healthcare team provided them with an organized self-management framework that encouraged and supported participation [11]. In diabetic management, diet, exercise, glucose measurement, weight monitoring, and medication administration are influenced, and in many instances effectively controlled, by patients. The CCM defines self-management support as collaboratively helping patients and families acquire the skills and confidence to manage their chronic illness, providing selfmanagement tools, and routinely assessing problems and accomplishments [7]. Data from multiple studies show that measures of disease treatment improve as selfmanagement efficacy improves [12]. Components of care such as medication compliance, diet, exercise, avoidance of negative behaviors have been shown to improve in chronic disease with effective self-management strategies [13-14]. Recent models of healthcare emphasize systematic approaches to care change. Bergeson and Dean note the importance of self-management support and the lack of effectiveness of education without a concurrent emphasis on building confidence and skills [15].
MS is a lifelong neurological disorder that affects persons during their peak work and reproductive years [16]. As in many other chronic diseases, individuals require ongoing care coordination, including medication, disease and symptom management, and education as well as strategies for addressing acute exacerbations. Multiple issues that emerge during the course of MS and cross specialty lines demand active participation by the person and his or her family or other caregivers [17]. A substantial need exists for practices that encourage healthy activity, ongoing disease management, improved perception of control, and symptom relief [18].

We undertook a systematic literature review on selfmanagement support in neurology, specifically reviewing implementation methodologies, measurements of efficacy and sustainability, implementations in the MS population, and potential future strategies for implementation of selfmanagement support in the population with MS. In this article, we review this literature search and summarize potential interventions specific to the population with MS.

\section{METHODS}

We conducted preliminary exploratory searches to identify self-management strategies reported in the Englishlanguage empirical literature from the years 1990 through 2009. We placed specific emphasis on identifying selfmanagement intervention strategies, measurement selection, neurological disorders to which the self-management programs have been applied, and intervention outcomes. After testing various search strings, we developed the final comprehensive search string to focus more narrowly on evidence of the effectiveness of self-management interventions. The search included the terms "self care" or "telemedicine" or "ambulatory monitoring" or "patient participation" or "self manag*" combined with either "multiple sclerosis," “stroke,” "spinal cord injury," "headache,” "epilepsy," "traumatic brain injury,” "amyotrophic lateral sclerosis," "Parkinson disease," or "Alzheimer disease” [1]. We chose those specific disorders to represent common chronic neurological disorders. We conducted searches in the following databases:

- Cochrane Database of Systematic Reviews

- PUBMED

- CINAHL

- PsycINFO

- EMBASE 
We compared search results with prior articles in our possession for completeness of the search strategy.

One author at each study site (Seattle, Washington, and Cleveland, Ohio) first reviewed each article abstract, and each decided independently whether it met the inclusion criteria for the study. We also included surveys of selfmanagement strategies, focus group findings of selfmanagement practices, and reviews of self-management in neurological disorders. We based inclusion of an article for the review on a systematic iterative process if they reported self-management interventions in neurologic disorders. We excluded single-case reports, commentaries, and editorials as well as articles without an explicit focus on selfmanagement. In several articles, the intervention focused exclusively on caregivers as opposed to individuals with illness (examples included interventions for Alzheimer disease and pediatrics); we also excluded these articles. Specific outcomes and targets of intervention did not form the basis for inclusion or exclusion. A coordinator reviewed the screening results and recommendations to include or exclude an abstract compared across sites. In instances where the coordinator found discrepancy in the recommendations, the original reviewers rereviewed and collectively discussed the abstract. The adjudication process occasionally included obtaining the full article for clarification or consulting a third reviewer and continuing discussion until consensus was reached in all cases.

\section{RESULTS}

Both research teams systematically and independently screened a total of 527 abstracts identified by the comprehensive search according to the predetermined criteria. We used these final abstracts to synthesize the literature to address the following questions:

- What is known about self-management strategies in neurological diseases?

- What strategies have been tried in populations?

- What outcome measures have been used?

- What outcome data are there for self-management strategies?

- What recommendations for future studies have been suggested?

\section{Data Synthesis}

After initial screening, we included 36 articles in the systematic evidence-based literature review process. We added an additional four articles from hand searches; two of these described the same study in different levels of detail, so we only used the more detailed article for this review. This resulted in a total of 39 evaluable studies (Figure 1). We collected information in a data table on study design, type of intervention, primary outcome, disease type, sample size (when included), follow-up time points, completion rate percent, and results. Table 1 describes the evidence for intervention classified according to the criteria of the American Academy of Neurology (AAN) Quality Standards Subcommittee and Therapeutics and Technology Assessment Committees [19].

We determined evidence ratings through an iterative evaluative process identical to that used to identify the articles. Articles were assigned to authors at each site for review. Each author (one at each study site) independently evaluated an assigned study and gave it an evidence rating (class I-IV evidence). The coordinator reviewed the results. In instances where there was a discrepancy in the rating, the two reviewers rereviewed and collectively discussed with occasional consultation from the group until consensus was reached in all cases.

\section{Data Synthesis Results}

Of the 39 articles meeting criteria for inclusion, we rated 3 as class I evidence, 2 as class II evidence, and 15 as class III evidence. We rated 19 articles as Class IV evidence (Tables 2 and 3).

The three class I evidence studies met the AAN criteria of being randomized controlled trials (RCTs) with at least single blinding (in both cases, raters were blinded to group allocation). All articles had explicit inclusion and exclusion criteria, accounted for all study participants, had more than 80 percent of study entrants complete the study phase, and had a primary endpoint measure. The two class II evidence articles were all RCTs with at least single-blind masking (usually rater blinded). These articles received a class II evidence rating because dropouts represented $>20$ percent of study participants [20] or they lacked a clearly defined primary outcome [21-23]. The 15 class III evidence articles received this ranking for two reasons. Eight were randomized trials but did not include any level of masking that the raters could judge from the publication. Six were cohort studies in which pre and post measures were used without control groups. Table 2 briefly summarizes all class I through III evidence articles.

Class IV evidence articles examined self-management in individuals with neurological disorders. These either 


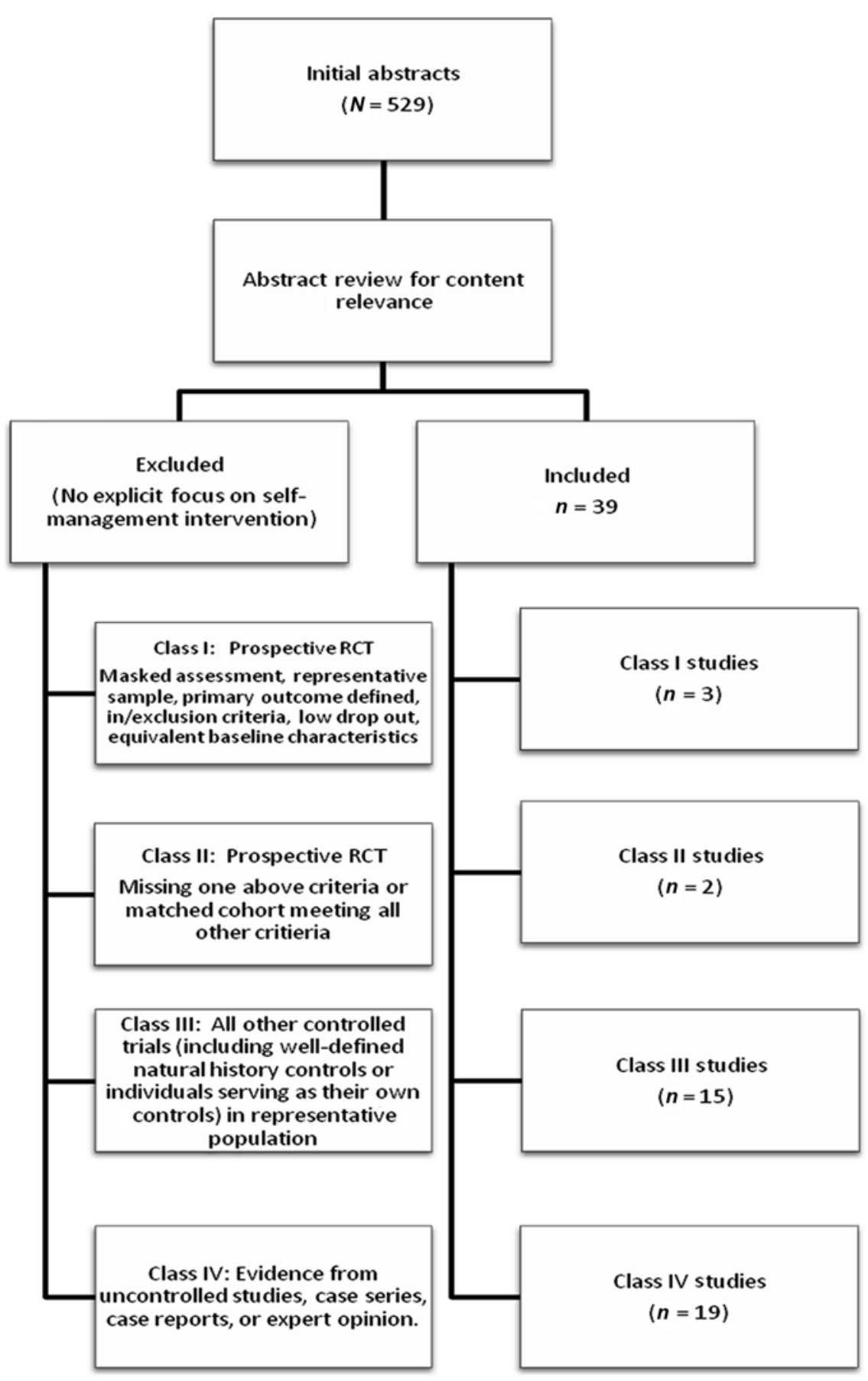

Figure 1.

Development of evidence tables. RCT $=$ randomized controlled trial.

described methodologies for self-management or were focused reviews. Note that we omitted one article from the final count because it described the same study as another article in a different level of detail but had no substantive change in results or conclusions [24].

\section{Self-Management Class I Evidence}

Bombardier et al. performed an RCT of telephone counseling for health promotion in people with MS residing in the community [25]. Treatment group participants underwent a motivational interview and goal-setting meeting and 
Table 1.

Evidence classification criteria. These criteria are taken from American Academy of Neurology Quality Standards Subcommittee and Therapeutics and Technology Assessment Committees.

Class

Criteria

I $\quad$ Prospective RCT with masked outcome assessment in representative population. Following criteria also required:

- Primary outcome clearly defined.

- Exclusion/inclusion criteria clearly defined.

- Adequate accounting for dropouts and crossovers with numbers sufficiently low to have minimal potential for bias (80\% retention in intervention and control groups).

- Relevant baseline characteristics presented and substantially equivalent among treatment groups or appropriate statistical adjustment for differences.

II Prospective matched group cohort study in representative population with masked outcome assessment that meets class I evidence criteria or RCT in representative population that lacks one class I evidence criteria.

III All other controlled trials (including well-defined natural history controls or individuals serving as their own controls) in representative population where outcome is independently assessed or independently derived by objective outcome measurement.

IV Evidence from uncontrolled studies, case series, case reports, or expert opinion.

RCT $=$ randomized controlled trial.

Table 2.

Systematic review of self-management strategies in neurological diseases.

\begin{tabular}{|c|c|c|c|c|c|c|c|}
\hline $\begin{array}{l}\text { Evidence } \\
\text { Class }\end{array}$ & Author & Date & Population & Intervention & $\mathbf{R}$ & $\mathbf{M}$ & Outcome \\
\hline $\mathrm{I}$ & Ashburn et al. [1] & 2007 & Parkinson disease & HBEP & $\mathrm{Y}$ & $\mathrm{Y}$ & Reduced falls trend \\
\hline I & Bombardier et al. [2] & 2008 & MS & $\begin{array}{l}\text { Telephone counseling for health } \\
\text { promotion }\end{array}$ & $\mathrm{Y}$ & $\mathrm{Y}$ & $\begin{array}{l}\text { Greater improvement in HPLPII } \\
\text { measures }\end{array}$ \\
\hline $\mathrm{I}$ & Hassett et al. [3] & 2009 & TBI & HBEP & $\mathrm{Y}$ & $\mathrm{Y}$ & $\begin{array}{l}\text { HBEP equivalent to fitness center } \\
\text { intervention in fitness outcomes }\end{array}$ \\
\hline II & Lemstra et al. [4] & 2002 & Migraine & Multidisciplinary intervention & $\mathrm{Y}$ & $\mathrm{Y}$ & $\begin{array}{l}\text { Improvements on multiple meas- } \\
\text { ures of pain and functional status }\end{array}$ \\
\hline II & O’Hara et al. [5] & 2002 & MS & Professionally guided self-care & $\mathrm{Y}$ & $\mathrm{Y}$ & SF-36 measure improvements \\
\hline III & Andersson et al. [6] & 2003 & Recurrent headache & $\begin{array}{l}\text { Telephone contact in addition to } \\
\text { self-help emails }\end{array}$ & $\mathrm{Y}$ & $\mathrm{N}$ & $\begin{array}{l}\text { No difference from self-help email } \\
\text { alone }\end{array}$ \\
\hline III & Barlow et al. [7] & 2009 & MS & Lay-led self-management & $\mathrm{Y}$ & $\mathrm{N}$ & $\begin{array}{l}\text { Improved self-management self- } \\
\text { efficacy }\end{array}$ \\
\hline III & Bond et al. [8] & 2004 & Headache & $\begin{array}{l}\text { Self-efficacy videotape vs } \\
\text { information-only videotape }\end{array}$ & $\mathrm{Y}$ & $\mathrm{N}$ & $\begin{array}{l}\text { Increased headache management } \\
\text { self-efficacy }\end{array}$ \\
\hline III & Cha et al. [9] & 2007 & MS & Home telemanagement & $\mathrm{N}$ & $\mathrm{N}$ & High acceptance rate \\
\hline III & Devineni \& Blanchard [10] & 2005 & Headache & Internet-based treatment & $\mathrm{Y}$ & $\mathrm{N}$ & Improved self-reports of headache \\
\hline III & Ghahari et al. [11] & 2009 & Neurologic conditions & $\begin{array}{l}\text { Internet-based fatigue self- } \\
\text { management program }\end{array}$ & $\mathrm{N}$ & $\mathrm{N}$ & Improvement in FIS score \\
\hline III & Hughes et al. [12] & 2006 & Women with disabilities & Stress self-management course & $\mathrm{Y}$ & $\mathrm{N}$ & $\begin{array}{l}\text { Improvement of pain and role- } \\
\text { limitation measures }\end{array}$ \\
\hline III & John et al. [13] & 2007 & Migraine & Yoga therapy & $\mathrm{Y}$ & $\mathrm{N}$ & Reduced headache intensity \\
\hline III & Jones et al. [14] & 2009 & Stroke & Stroke self-management program & $\mathrm{N}$ & $\mathrm{N}$ & Improvement in stroke self-efficacy \\
\hline III & McAuley et al. [15] & 2007 & MS & Efficiency-enhancement exercise & $\mathrm{Y}$ & $\mathrm{N}$ & No difference \\
\hline III & Mérelle et al. [16] & 2008 & Migraine & Lay-trainer program & $\mathrm{Y}$ & $\mathrm{N}$ & Strengthened perceived control \\
\hline III & Navipour et al. [17] & 2006 & MS & Self-care program & $\mathrm{N}$ & $\mathrm{N}$ & Improvement in self-esteem score \\
\hline III & Stuifbergen et al. [18] & 2003 & MS & Wellness intervention & $\mathrm{Y}$ & $\mathrm{N}$ & $\begin{array}{l}\text { Improvement in self-efficacy for } \\
\text { health behaviors }\end{array}$ \\
\hline III & Wassem \& Dudley [19] & 2003 & MS & Intensive outpatient program & $\mathrm{N}$ & $\mathrm{N}$ & $\begin{array}{l}\text { Improvement in symptom } \\
\text { management }\end{array}$ \\
\hline III & Shevil \& Finlayson [20] & 2009 & MS & Cognitive intervention program & $\mathrm{N}$ & $\mathrm{N}$ & $\begin{array}{l}\text { Improvement in self-efficacy } \\
\text { measures }\end{array}$ \\
\hline
\end{tabular}




\section{JRRD, Volume 48, Number 9, 2011}

Table 2. (cont)

Systematic review of self-management strategies in neurological diseases.

1. Ashburn A, Fazakarley L, Ballinger C, Pickering R, McLellan LD, Fitton C. A randomised controlled trial of a home based exercise programme to reduce the risk of falling among people with Parkinson's disease. J Neurol Neurosurg Psychiatry. 2007;78(7):678-84. [PMID: 17119004] DOI:10.1136/jnnp.2006.099333

2. Bombardier CH, Cunniffe M, Wadhwani R, Gibbons LE, Blake KD, Kraft GH. The efficacy of telephone counseling for health promotion in people with multiple sclerosis: A randomized controlled trial. Arch Phys Med Rehabil. 2008;89(10):1849-56. [PMID: 18929012]

DOI:10.1016/j.apmr.2008.03.021

3. Hassett LM, Moseley AM, Tate RL, Harmer AR, Fairbairn TJ, Leung J. Efficacy of a fitness centre-based exercise programme compared with a home-based exercise programme in traumatic brain injury: A randomized controlled trial. J Rehabil Med. 2009;41(4):247-55. [PMID: 19247544] DOI:10.2340/16501977-0316

4. Lemstra M, Stewart B, Olszynski WP. Effectiveness of multidisciplinary intervention in the treatment of migraine: A randomized clinical trial. Headache. 2002;42(9):845-54. [PMID: 12390609] DOI:10.1046/j.1526-4610.2002.02202.x

5. O’Hara L, Cadbury H, De SL, Ide L. Evaluation of the effectiveness of professionally guided self-care for people with multiple sclerosis living in the community: A randomized controlled trial. Clin Rehabil. 2002;16(2):119-28. [PMID: 11911510] DOI:10.1191/0269215502cr478oa

6. Andersson G, Lundström P, Ström L. Internet-based treatment of headache: Does telephone contact add anything? Headache. 2003;43(4):353-61. [PMID: 12656706] DOI:10.1046/j.1526-4610.2003.03070.x

7. Barlow J, Turner A, Edwards R, Gilchrist M. A randomised controlled trial of lay-led self-management for people with multiple sclerosis. Patient Educ Couns. 2009;77(1):81-89. [PMID: 19321290] DOI:10.1016/j.pec.2009.02.009

8. Bond DS, Durrant L, Digre KB, Baggaley SK, Rubingh C. Impact of a self-help intervention on performance of headache management behaviors: A self-efficacy approach. Internet J Allied Health Sci Prac. 2004;2(1).

9. Cha E, Castro HK, Provance P, Finkelstein J. Acceptance of home telemanagement is high in patients with multiple sclerosis. AMIA Annu Symp Proc. $2007: 893$. [PMID: 18693994]

10. Devineni T, Blanchard EB. A randomized controlled trial of an Internet-based treatment for chronic headache. Behav Res Ther. 2005;43(3):277-92. [PMID: 15680926] DOI:10.1016/j.brat.2004.01.008

11. Ghahari S, Packer TL, Passmore AE. Development, standardisation and pilot testing of an online fatigue self-management program. Disabil Rehabil. 2009;31(21):1762-72. [PMID: 19479510] DOI:10.1080/09638280902751956

12. Hughes RB, Robinson-Whelen S, Taylor HB, Hall JW. Stress self-management: An intervention for women with physical disabilities. Womens Health Issues. 2006;16(6):389-99. [PMID: 17188222] DOI:10.1016/j.whi.2006.08.003

13. John PJ, Sharma N, Sharma CM, Kankane A. Effectiveness of yoga therapy in the treatment of migraine without aura: A randomized controlled trial. Headache. 2007;47(5):654-61. [PMID: 17501846] DOI:10.1111/j.1526-4610.2007.00789.x

14. Jones F, Mandy A, Partridge C. Changing self-efficacy in individuals following a first time stroke: Preliminary study of a novel self-management intervention. Clin Rehabil. 2009;23(6):522-33. [PMID: 19403556] DOI:10.1177/0269215508101749

15. McAuley E, Motl RW, Morris KS, Hu L, Doerksen SE, Elavsky S, Konopack JF. Enhancing physical activity adherence and well-being in multiple sclerosis: A randomised controlled trial. Mult Scler. 2007;13(5):652-59. [PMID: 17548446] DOI:10.1177/1352458506072188

16. Mérelle SY, Sorbi MJ, Van Doornen LJ, Passchier J. Migraine patients as trainers of their fellow patients in non-pharmacological preventive attack management: Short-term effects of a randomized controlled trial. Cephalalgia. 2008;28(2):127-38. [PMID: 18197883]

17. Navipour H, Madani H, Mohebbi MR, Navipour R, Roozbayani P, Paydar A. Improved fatigue in individuals with multiple sclerosis after participating in a short-term self-care programme. NeuroRehabilitation. 2006;21(1):37-41. [PMID: 16720936]

18. Stuifbergen AK, Becker H, Blozis S, Timmerman G, Kullberg V. A randomized clinical trial of a wellness intervention for women with multiple sclerosis. Arch Phys Med Rehabil. 2003;84(4):467-76. [PMID: 12690582] DOI:10.1053/apmr.2003.50028

19. Wassem R, Dudley W. Symptom management and adjustment of patients with multiple sclerosis: A 4-year longitudinal intervention study. Clin Nurs Res. 2003; 12(1):102-17. [PMID: 12583502] DOI:10.1177/1054773803238743

20. Shevil E, Finlayson M. Process evaluation of a self-management cognitive program for persons with multiple sclerosis. Patient Educ Couns. 2009;76(1):77-83. [PMID: 19118971] DOI:10.1016/j.pec.2008.11.007

FIS = Fatigue Impact Scale, HBEP = home-based exercise program, HPLPII = Health Promotion Lifestyle Profile II, M = masked, MS = multiple sclerosis, $\mathrm{N}=$ no, $\mathrm{R}$ = randomized, SF-36 = 36-Item Short Form Health Survey, TBI = traumatic brain injury, $\mathrm{Y}=$ yes. 
Table 3.

Studies of self-management strategies in neurological disorders (class IV evidence).

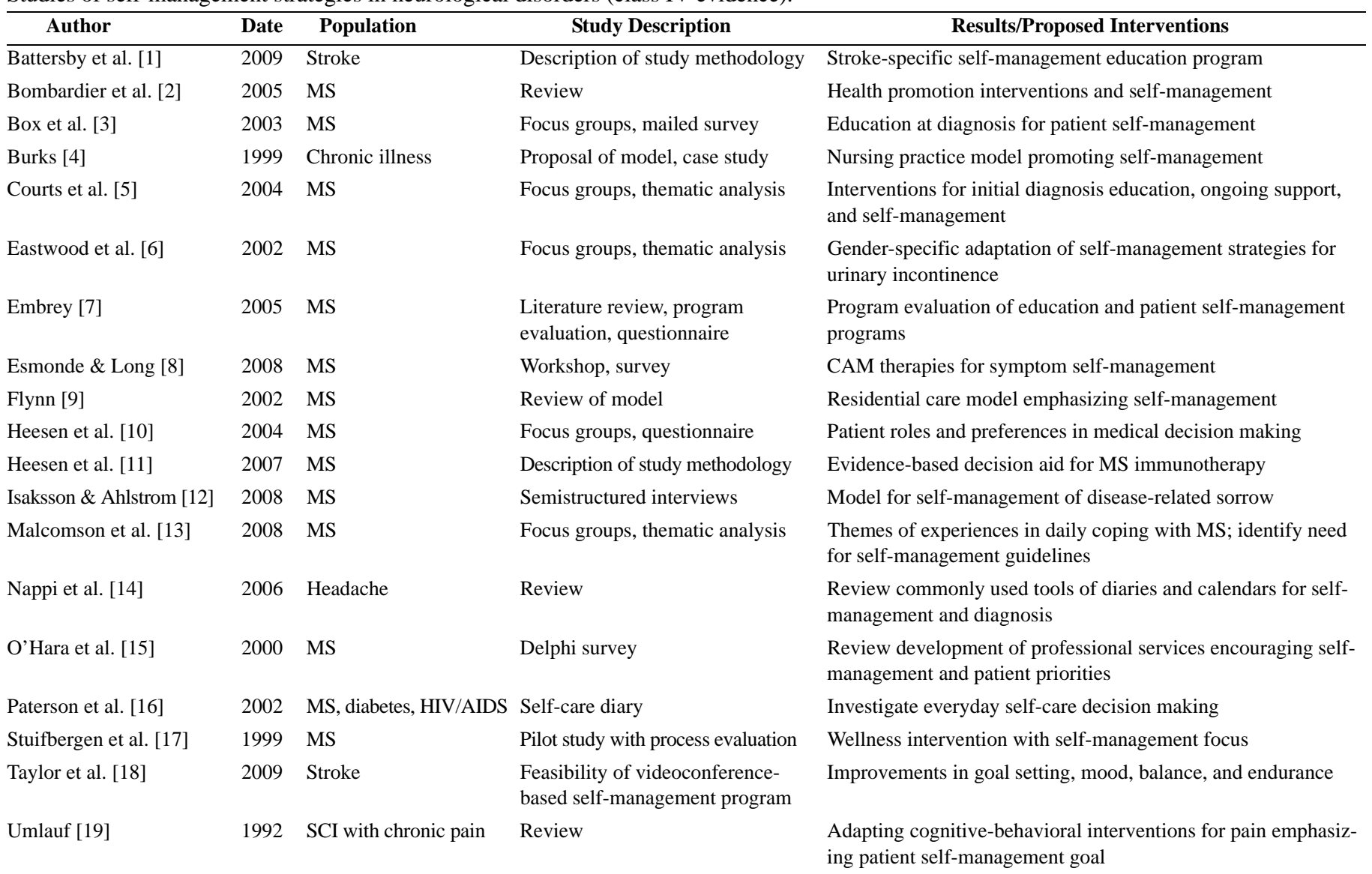

1. Battersby M, Hoffmann S, Cadilhac D, Osborne R, Lalor E, Lindley R. “Getting your life back on track after stroke”: A phase II multi-centered, single-blind, randomized, controlled trial of the Stroke Self-Management Program vs. the Stanford Chronic Condition Self-Management Program or standard care in stroke survivors. Int J Stroke. 2009;4(2):137-44. [PMID: 19383056] DOI:10.1111/j.1747-4949.2009.00261.X

2. Bombardier CH, Wadhwani R, LaRotonda C. Health promotion in people with multiple sclerosis. Phys Med Rehabil Clin N Am. 2005;16(2):557-70. [PMID: 15893686] DOI:10.1016/j.pmr.2005.01.002

3. Box V, Hepworth M, Harrison J. Identifying information needs of people with multiple sclerosis. Nurs Times. 2003;99(49):32-36. [PMID: 14705344]

4. Burks KJ. A nursing practice model for chronic illness. Rehabil Nurs. 1999;24(5):197-200. [PMID: 10754910]

5. Courts NF, Buchanan EM, Werstlein PO. Focus groups: The lived experience of participants with multiple sclerosis. J Neurosci Nurs. 2004;36(1):42-47. [PMID: 14998106] DOI:10.1097/01376517-200402000-00007

6. Eastwood S, Kralik D, Koch T. Compromising and containing: Self-management strategies used by men and women who live with multiple sclerosis and urinary incontinence. Aust J Holist Nurs. 2002;9(1):33-43. [PMID: 12056315]

7.Embrey N. Self-management education in multiple sclerosis services. Nurs Times. 2005;101(34):34-36. [PMID: 16149703]

8. Esmonde L, Long AF. Complementary therapy use by persons with multiple sclerosis: Benefits and research priorities. Complement Ther Clin Pract. 2008; 14(3):176-84. [PMID: 18640629] DOI:10.1016/j.ctcp.2008.03.001

9. Flynn S. Multiple sclerosis: The Treetops model of residential care. Br J Nurs. 2002;11(9):635-42. [PMID: 12048478$]$

10. Heesen C, Kasper J, Segal J, Köpke S, Muhlhauser I. Decisional role preferences, risk knowledge and information interests in patients with multiple sclerosis. Mult Scler. 2004;10(6):643-50. [PMID: 15584489] DOI:10.1191/1352458504ms1112oa

11. Heesen C, Köpke S, Richter T, Kasper J. Shared decision making and self-management in multiple sclerosis—A consequence of evidence. J Neurol. 2007;254 Suppl 2:II116-21. [PMID: 17503119] DOI:10.1007/s00415-007-2028-z 
Table 3. (cont)

Studies of self-management strategies in neurological disorders (class IV evidence).

12. Isaksson AK, Ahlstrom G. Managing chronic sorrow: Experiences of patients with multiple sclerosis. J Neurosci Nurs. 2008;40(3):180-91. [PMID: 18578277] DOI:10.1097/01376517-200806000-00009

13. Malcomson KS, Lowe-Strong AS, Dunwoody L. What can we learn from the personal insights of individuals living and coping with multiple sclerosis? Disabil Rehabil. 2008;30(9):662-74. [PMID: 17852315] DOI:10.1080/09638280701400730

14. Nappi G, Jensen R, Nappi RE, Sances G, Torelli P, Olesen J. Diaries and calendars for migraine. A review. Cephalalgia. 2006;26(8):905-16. [PMID: 16886925] DOI:10.1111/j.1468-2982.2006.01155.X

15. O’Hara L, De Souza LH, Ide L. A Delphi study of self-care in a community population of people with multiple sclerosis. Clin Rehabil. 2000;14(1):62-71. [PMID: 10688346] DOI:10.1191/026921500666135189

16. Paterson B, Thorne S, Russell C. Disease-specific influences on meaning and significance in self-care decision-making in chronic illness. Can J Nurs Res. 2002; 34(3):61-74. [PMID: 12425011]

17. Stuifbergen A, Becker H, Rogers S, Timmerman G, Kullberg V. Promoting wellness for women with multiple sclerosis. J Neurosci Nurs. 1999;31(2):73-79. [PMID: 14964606] DOI:10.1097/01376517-199904000-00003

18. Taylor DM, Cameron JI, Walsh L, McEwen S, Kagan A, Steiner DL, Huijbregts MP. Exploring the feasibility of videoconference delivery of a self-management program to rural participants with stroke. Telemed J E Health. 2009;15(7):646-54. [PMID: 19694589] DOI:10.1089/tmj.2008.0165

19. Umlauf RL. Psychological interventions for chronic pain following spinal cord injury. Clin J Pain. 1992;8(2):111-18. [PMID: 1633374] DOI:10.1097/00002508-199206000-00008

CAM = computer-aided model, HIV/AIDS = human immunodeficiency virus/acquired immunodeficiency syndrome, MS = multiple sclerosis, $\mathrm{SCI}=$ spinal cord injury.

a series of five follow-up telephone counseling sessions over 12 weeks. All participants were accounted for using a CONSORT flowchart. A trained research assistant masked to group assignment assessed outcomes for both groups at 12 weeks. The primary outcome was effect on the Health Promoting Lifestyle Profile II inventory. Overall selfreported health promotion activities significantly increased in the treatment group and were stable in the control group. Specific areas of change included physical activity, spiritual growth, and stress management.

Ashburn et al. reported on an RCT of a home-based exercise program to reduce falling in the population with Parkinson disease [26]. Participants were recruited from two National Health Service trusts in Dorset, United Kingdom, with well-defined inclusion and exclusion criteria. The study was randomized with a blinded assessor. All dropouts were accounted for, and the completion rate was 90 percent. Subjects were assessed at baseline, 8 weeks, and 6 months. A physical therapist designed an individualized exercise program, and a treating researcher encouraged continuing the exercises on a monthly telephone call. The control group undertook usual care and was offered exercise advice at the end of the study. There was a trend toward reduced fall rate in the treatment group that did not reach statistical significance.

Hassett et al. performed a multicenter, assessor-blinded, parallel group RCT of fitness-center-based exercise com- pared with a home-based exercise program for individuals with traumatic brain injury [27]. They accounted for all participants and the primary outcome measure of cardiorespiratory fitness was the $20 \mathrm{~m}$ shuttle test. They found that both groups improved in fitness equally, despite the fact that adherence to the exercise program was better in the fitness center-based group.

\section{Self-Management Class II Evidence}

Lemstra et al. describe a randomized clinical trial of a multidisciplinary intervention in migraine treatment [21]. Individuals were randomized to an intervention group (group-supervised exercise therapy sessions, stress management, relaxation therapy, dietary lecture, massage therapy) and a control group. The outcome assessor was blinded to the group allocation. Intention-to-treat analysis showed a significant change in self-perceived pain, pain intensity, and quality of life, among other measures. Lemstra et al. note that quality of life improvements were possible with a lowcost multidisciplinary group intervention.

O'Hara et al. undertook a randomized single-blind trial of a professionally guided self-care program for individuals with MS living in the community [28]. The intervention group used an information booklet to discuss self-care based on client priorities. There was no primary outcome measure. The intervention group at 6-month follow-up showed better 36-Item Short Form Health Survey (SF-36) 
scores for mental health and vitality and considered help with daily activities to be less essential.

\section{Self-Management Class III Evidence}

Among the class III evidence studies were both randomized trials and cohort trials without controls (Table 2). The randomized trials are reviewed in more detail. Four of the nine studies examined self-management interventions for MS.

Hughes et al. evaluated the efficacy of a stressmanagement intervention for women with disabilities (MS, spinal cord injury, and arthritis) using a randomized, unblinded design [29]. Participants took part in a 6-week workshop with weekly 2.5-hour group sessions discussing stress, time management, social support and relationships, and physical care. This study included a comparison group of a wait-list control. Differences favoring the intervention condition were found in perceived stress and mental health at the 3-month follow-up.

Barlow et al. conducted a randomized trial of a layled self-management intervention for persons with MS [30]. Individuals in the intervention condition participated in six weekly sessions delivered in community settings by lay tutors. Topics were generic, but at the same time salient to MS, and included discussions of exercise, pain, fatigue, relaxation, depression, nutrition, and communication. Individuals were encouraged to set personal goals for the coming week that were relevant, achievable, and measurable in the short term. At the 4-month followup, participants in the intervention condition reported better self-management, self-efficacy, and physical functioning than wait-list controls.

Two studies specifically examined physical well-being in individuals with MS. Stuifbergen et al. conducted a wellness intervention in which women with MS participated in an 8 week class with bimonthly telephone follow-up for 3 months [31]. Treatment focused on education and skill building as well as support for identifying and achieving individual goals for lifestyle change. The study found that differential outcomes favoring the intervention for overall health behaviors, self-efficacy, and the mental health and pain scales of the SF-36. McAuley et al. conducted a selfefficacy intervention intended to enhance participation in an exercise program [32]. Individuals in both the intervention and control conditions participated in a 12-week exercise program consisting of supervised hour-long exercise sessions three times per week. Individuals in the intervention condition participated in a series of workshops that included lectures, discussion, and brief homework assignments that targeted goal setting, overcoming barriers, monitoring performance, and seeking social support. The primary outcome, attendance at exercise classes, did not differ between the treatment and control conditions, though again, the sample size of 15 suggested that the study was underpowered to examine this question. Individuals in the intervention condition reportedly retained better satisfaction with life over time than their counterparts in the control condition.

The remaining five studies examined self-management interventions for headaches [20,33-36]. Treatments included an Internet-based self-help program with therapist-initiated telephone contacts [20], videotape training intended to promote self-efficacy [36], an Internet-based education program [33], yoga [34], and home-based training by lay providers with migraine [35]. Outcomes differed across studies, but included headache symptoms and related disability [20,3334] as well as perceptions of self-efficacy [35] and selfmanagement behaviors [36]. Of the studies examining headache symptoms and disability, two report significant treatment effects [33-34]. One study notes a trend favoring treatment [35], and the other shows no comparative benefit of treatment [20], but data were reported on only 30 participants and the analyses were likely underpowered. Two studies show differential improvements in intermediate outcomes supporting self-management, including selfefficacy [35] and the use of self-management behavior [36].

\section{Self-Management Class IV Evidence}

We included class IV evidence articles if they reflected self-management strategies directed at individuals with neurological disorders. Table $\mathbf{3}$ shows a variety of articles reflecting the broad range of methodologies. Many of these describe the chronic disease experience, self-care decision making, education programs, or CCMs. Many articles emphasize a consumer-based approach to care, and a variety of potential interventions to study in a more robust fashion emerge (Table 3). Such articles provide preliminary data or contextual information on the experience of self-care in such diseases but do not provide evidence to support specific treatment interventions without further corroboration.

\section{DISCUSSION}

New strategies to engage, educate, and empower individuals with chronic neurological disease and their caregiver hold promise to improve care. Self-management 
programs may foster awareness and skills to help prevent negative outcomes, such as falls, and encourage positive health behavior, such as exercise. These health-promoting behaviors may ultimately increase the effectiveness and value per dollar of medical care [37]. The emerging use of technologies such as the telephone and home-based and handheld telehealth devices may provide additional opportunities for support and communication between individuals and their healthcare providers. By considering the continuum of chronic care, strategies that take into account the range of long-term problems and needs promise to provide a better system of care than the present patchwork of care can.

Our systematic review was designed to inform the development of self-management interventions in MS. To do so required expansion into larger areas of neurological disability. The focus of these interventions-health promotion, fall prevention, exercise, stress management, diet, and patient-directed self-care-are all specifically relevant to the care of individuals with MS and reflect a promising variety of potential treatment options.

However, we found only three articles that met AAN criteria for a class I evidence study. This both suggests an existing need for more strictly designed and performed studies of self-management strategies in this population and demonstrates that such studies can be feasible and efficacious. Therefore, a rich field of interventions can be more stringently evaluated in the future. We also recommend that measurable outcomes that are important to individuals and families, such as fall prevention, reduced healthcare costs, improved quality of life, and delayed nursing home entry, be used to clarify the true effect of these interventions on person-centered care rather than more abstract scales. Figure 2 provides suggestions for design elements to include in future self-management studies to improve the potential rigor of these studies.

Potential self-management interventions to consider for the population with MS include self-managed exercise programs, motivational interviewing and goal setting, group and/or individual self-management sessions, Internet-based self-management strategies, telephone prompting strategies, lay-led self-management, and self-managed wellness programs. Promising intervention targets include diet; exercise; medication adherence; smoking cessation; alcohol reduction; and the ongoing management of fatigue, stress, pain, and cognition.

Results of this review are subject to limitations. The diversity of self-management interventions and the limited number of published studies makes it difficult to compare the efficacy of different treatment strategies.

1. Explicit designation of research question, including population, intervention, comparison group, and primary and secondary outcomes measures.

2. Randomization strategy with explicit statement of measures used to avoid allocation bias.

3. Blinding strategy where possible. If not possible, then rater/observer blinding should be explicitly defined.

4. Inclusion of figure with flow chart of patient and control disposition using CONSORT methodology."

5. Use of intention-to-treat analysis.

6. Inclusion of baseline comparison of demographic and disease factors in patient and control groups to ensure comparable baseline characteristics (e.g., disease type or stage, age, sex, other factors such as educational level or ethnicity as applicable).

7. Results focused on primary outcome measures.

8. Specific discussion about methodological issues and challenges to study conduct.

9. Specific discussion of how primary outcome measures relate to patient-oriented outcomes (e.g., satisfaction, disability measures, pain measures). Including measures of quality of life specific to disease process would be one strategy.

Figure 2.

Proposed methodological strategies for future self-management studies in chronic neurological disorders. *'Schulz KF, Altman DG, Moher D; CONSORT Group. CONSORT 2010 statement: Updated guidelines for reporting parallel group randomized trials. Ann Intern Med. 2010;152(11): 726-32. [PMID: 20335313] 
Similarly, the heterogeneity of outcomes targeted by self-management interventions complicates efforts to establish a common metric of success (e.g., self-efficacy, quality of life).

As healthcare system evaluations by payors and governmental agencies move toward evaluating the totality of care for different populations, it makes sense to more intensively and objectively explore ways for individuals and families to manage their own care in positive, productive ways. We hope that studies of self-management lead the management of chronic neurological diseases to a better path for the future [38-39].

\section{CONCLUSIONS}

This systematic review found limited but promising evidence supporting the value of programs designed to promote self-management in MS and other neurological diseases. Future research should focus on interventions that integrate self-management into ongoing chronic illness care and make use of outcomes directly relevant to individuals coping with illness, such as quality of life.

\section{ACKNOWLEDGMENTS}

\section{Author Contributions:}

Study concept and design: A. D. Rae-Grant, D. Miller.

Acquisition of data: A. Sloan, J. Hunziker.

Analysis and interpretation of data: A. D. Rae-Grant, D. Miller,

A. P. Turner.

Drafting of manuscript: A. D. Rae-Grant, A. P. Turner.

Critical revision of manuscript for important intellectual content:

A. D. Rae-Grant, A. P. Turner, A. Sloan, D. Miller, J. Hunziker,

J. K. Haselkorn.

Administrative, technical, or material support: A. P. Turner, A. Sloan, J. Hunziker.

Study supervision: A. D. Rae-Grant, J. K. Haselkorn, A. P. Turner.

Financial Disclosures: The authors have declared that no competing interests exist.

Funding/Support: This material was based on work supported by a Department of Veterans Affairs (VA) Rehabilitation Research and Development Service Career Development Award (grant B4927W to Dr. Turner). Additional support was provided by the VA MS Center of Excellence West.

\section{REFERENCES}

1. Noseworthy JH, Lucchinetti C, Rodriguez M, Weinshenker BG. Multiple sclerosis. N Engl J Med. 2000;343(13):938-52.

\section{[PMID: 11006371]}

\section{DOI:10.1056/NEJM200009283431307}

2. Aronson KJ. Quality of life among persons with multiple sclerosis and their caregivers. Neurology. 1997;48(1):74-80. [PMID: 9008497]

3. Williams RM, Turner AP, Hatzakis M Jr, Bowen JD, Rodriquez AA, Haselkorn JK. Prevalence and correlates of depression among veterans with multiple sclerosis. Neurology. 2005;64(1):75-80. [PMID: 1562907]

DOI:10.1212/01.WNL.0000148480.31424.2A

4. Hirsh AT, Turner AP, Ehde DM, Haselkorn JK. Prevalence and impact of pain in multiple sclerosis: Physical and psychologic contributors. Arch Phys Med Rehabil. 2009; 90(4):646-51. [PMID: 19345781]

DOI:10.1016/j.apmr.2008.10.019

5. Chiaravalloti ND, Deluca, J. Cognition and multiple sclerosis: Assessment and treatment. In: Frank RG, Rosenthal M, Caplan B, editors. Handbook of rehabilitation psychology. 2nd ed. Washington (DC): American Psychological Association; 2010. p. 133-44.

6. Bodenheimer T, Lorig K, Holman H, Grumbach K. Patient self-management of chronic disease in primary care. JAMA. 2002;288(19):2469-75. [PMID: 12435261]

DOI:10.1001/jama.288.19.2469

7. Bodenheimer T, Wagner EH, Grumbach K. Improving primary care for patients with chronic illness. JAMA. 2002; 288(14):1775-79. [PMID: 12365965]

DOI:10.1001/jama.288.14.1775

8. Mohler PJ, Mohler NB. Improving chronic illness care: Lessons learned in a private practice. Fam Pract Manag. 2005;12(10):50-56. [PMID: 16366442]

9. Bonomi AE, Wagner EH, Glasgow RE, VonKorff M. Assessment of chronic illness care (ACIC): A practical tool to measure quality improvement. Health Serv Res. 2002; 37(3):791-820. [PMID: 12132606] DOI:10.1111/1475-6773.00049

10. Glasgow RE, Wagner EH, Schaefer J, Mahoney LD, Reid RJ, Greene SM. Development and validation of the Patient Assessment of Chronic Illness Care (PACIC). Med Care. 2005;43(5):436-44. [PMID: 15838407]

DOI:10.1097/01.mlr.0000160375.47920.8c

11. Lorig KR, Holman H. Self-management education: History, definition, outcomes, and mechanisms. Ann Behav Med. 2003;26(1):1-7. [PMID: 12867348] DOI:10.1207/S15324796ABM2601 01

12. Marks R, Allegrante JP, Lorig K. A review and synthesis of research evidence for self-efficacy-enhancing interventions for reducing chronic disability: Implications for health education practice (part II). Health Promot Pract. 2005;6(2): 148-56. [PMID: 15855284] DOI:10.1177/1524839904266792 
13. Bodenheimer T, Wagner EH, Grumbach K. Improving primary care for patients with chronic illness: The Chronic Care Model, part 2. JAMA. 2002;288(15):1909-14.

[PMID: 12377092]

DOI:10.1001/jama.288.15.1909

14. Newman S, Steed L, Mulligan K. Self-management interventions for chronic illness. Lancet. 2004;364(9444):1523-37. [PMID: 15500899] DOI:10.1016/S0140-6736(04)17277-2

15. Bergeson SC, Dean JD. A systems approach to patientcentered care. JAMA. 2006;296(23):2848-51.

[PMID: 17179462]

DOI:10.1001/jama.296.23.2848

16. Fox RJ, Bethoux F, Goldman MD, Cohen JA. Multiple sclerosis: Advances in understanding, diagnosing, and treating the underlying disease. Cleve Clin J Med. 2006;73:91-102.

[PMID: 16444920]

DOI:10.3949/ccjm.73.1.91

17. Carton H, Loos R, Pacolet J, Versieck K, Vlietinck R. Utilisation and cost of professional care and assistance according to disability of patients with multiple sclerosis in Flanders (Belgium). J Neurol Neurosurg Psychiatry. 1998; 64(4):444-50. [PMID: 9576533]

DOI:10.1136/jnnp.64.4.444

18. Tattersall RL. The expert patient: A new approach to chronic disease management for the twenty-first century. Clin Med. 2002;2(3):227-29. [PMID: 12108472]

19. Edlund W, Gronseth G, So Y, Franklin G. Clinical practice guideline process manual. St. Paul (MN): American Academy of Neurology; 2004.

20. Andersson G, Lundström P, Ström L. Internet-based treatment of headache: Does telephone contact add anything? Headache. 2003;43(4):353-61. [PMID: 12656706$]$ DOI:10.1046/j.1526-4610.2003.03070.x

21. Lemstra M, Stewart B, Olszynski WP. Effectiveness of multidisciplinary intervention in the treatment of migraine: A randomized clinical trial. Headache. 2002;42(9):845-54. [PMID: 12390609] DOI:10.1046/j.1526-4610.2002.02202.X

22. Mahoney DF, Tarlow BJ, Jones RN. Effects of an automated telephone support system on caregiver burden and anxiety: Findings from the REACH for TLC intervention study. Gerontologist. 2003;43(4):556-67. [PMID: 12937334] DOI:10.1093/geront/43.4.556

23. O’Hara L, De Souza LH, Ide L. A Delphi study of self-care in a community population of people with multiple sclerosis. Clin Rehabil. 2000;14(1):62-71. [PMID: 10688346] DOI:10.1191/026921500666135189

24. Shevil E, Finlayson M. Process evaluation of a selfmanagement cognitive program for persons with multiple sclerosis. Patient Educ Couns. 2009;76(1):77-83.

\section{[PMID: 19118971]}

DOI:10.1016/j.pec.2008.11.007

25. Bombardier CH, Cunniffe M, Wadhwani R, Gibbons LE, Blake KD, Kraft GH. The efficacy of telephone counseling for health promotion in people with multiple sclerosis: A randomized controlled trial. Arch Phys Med Rehabil. 2008; 89(10):1849-56. [PMID: 18929012]

DOI:10.1016/j.apmr.2008.03.021

26. Ashburn A, Fazakarley L, Ballinger C, Pickering R, McLellan LD, Fitton C. A randomised controlled trial of a home based exercise programme to reduce the risk of falling among people with Parkinson's disease. J Neurol Neurosurg Psychiatry. 2007;78(7):678-84.

[PMID: 17119004]

DOI:10.1136/jnnp.2006.099333

27. Hassett LM, Moseley AM, Tate RL, Harmer AR, Fairbairn TJ, Leung J. Efficacy of a fitness centre-based exercise programme compared with a home-based exercise programme in traumatic brain injury: A randomized controlled trial. J Rehabil Med. 2009;41(4):247-55. [PMID: 19247544]

DOI:10.2340/16501977-0316

28. O’Hara L, Cadbury H, De SL, Ide L. Evaluation of the effectiveness of professionally guided self-care for people with multiple sclerosis living in the community: A randomized controlled trial. Clin Rehabil. 2002;16(2):119-28.

[PMID: 11911510]

DOI:10.1191/0269215502cr478oa

29. Hughes RB, Robinson-Whelen S, Taylor HB, Hall JW. Stress self-management: An intervention for women with physical disabilities. Womens Health Issues. 2006;16(6): 389-99. [PMID: 17188222]

DOI:10.1016/j.whi.2006.08.003

30. Barlow J, Turner A, Edwards R, Gilchrist M. A randomised controlled trial of lay-led self-management for people with multiple sclerosis. Patient Educ Couns. 2009;77(1):81-89. [PMID: 19321290]

DOI:10.1016/j.pec.2009.02.009

31. Stuifbergen AK, Becker H, Blozis S, Timmerman G, Kullberg V. A randomized clinical trial of a wellness intervention for women with multiple sclerosis. Arch Phys Med Rehabil. 2003;84(4):467-76. [PMID: 12690582] DOI:10.1053/apmr.2003.50028

32. McAuley E, Motl RW, Morris KS, Hu L, Doerksen SE, Elavsky S, Konopack JF. Enhancing physical activity adherence and well-being in multiple sclerosis: A randomised controlled trial. Mult Scler. 2007;13(5):652-59.

[PMID: 17548446]

DOI:10.1177/1352458506072188

33. Devineni T, Blanchard EB. A randomized controlled trial of an Internet-based treatment for chronic headache. Behav Res Ther. 2005;43(3):277-92. [PMID: 15680926] DOI:10.1016/j.brat.2004.01.008 
34. John PJ, Sharma N, Sharma CM, Kankane A. Effectiveness of yoga therapy in the treatment of migraine without aura: A randomized controlled trial. Headache. 2007;47(5):654-61. [PMID: 17501846] DOI:10.1111/j.1526-4610.2007.00789.x

35. Mérelle SY, Sorbi MJ, Van Doornen LJ, Passchier J. Migraine patients as trainers of their fellow patients in nonpharmacological preventive attack management: Shortterm effects of a randomized controlled trial. Cephalalgia. 2008;28(2):127-38. [PMID: 18197883]

36. Bond DS, Durrant L, Digre KB, Baggaley SK, Rubingh C. Impact of a self-help intervention on performance of headache management behaviors: A self-efficacy approach. Internet J Allied Health Sci Prac. 2004;2(1).

37. Fireman B, Bartlett J, Selby J. Can disease management reduce health care costs by improving quality? Health Aff (Millwood). 2004;23(6):63-75. [PMID: 15584100] DOI:10.1377/hlthaff.23.6.63

38. Thorne SE, Ternulf Nyhlin K, Paterson BL. Attitudes toward patient expertise in chronic illness. Int J Nurs Stud.
2000;37(4):303-311. [PMID: 10760537]

DOI:10.1016/S0020-7489(00)00007-9

39. Lorig K. Self-management of chronic illness: A model for the future. Generations. 1993;17:11-14.

Submitted for publication August 23, 2010. Accepted in revised form March 25, 2011.

This article and any supplementary material should be cited as follows:

Rae-Grant AD, Turner AP, Sloan A, Miller D, Hunziker J, Haselkorn JK. Self-management in neurological disorders: Systematic review of the literature and potential interventions in multiple sclerosis care. J Rehabil Res Dev. 2011; 48(9):1087-1100.

DOI:10.1682/JRRD.2010.08.0159

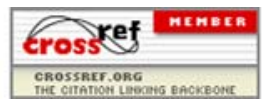


